\title{
Immigrants' Satisfaction from the National Health System in Greece: In the Quest of the Contributing Factors
}

\author{
Athanassios Vozikis*, Maria Siganou \\ Economics Department, University of Piraeus, Piraeus, Greece \\ Email: *avozik@unipi.gr
}

Received 7 October 2015; accepted 8 November 2015; published 11 November 2015

Copyright (C) 2015 by authors and Scientific Research Publishing Inc.

This work is licensed under the Creative Commons Attribution International License (CC BY). http://creativecommons.org/licenses/by/4.0/

(c) (i) Open Access

\begin{abstract}
Immigrants deserve special attention as they constitute a very sensitive social group, facing an increasing risk of social exclusion. The access of immigrants to health services is one of the most important factors, which contributes to their integration into the society of induction. The purpose of this study is to track and assess the immigrants' satisfaction from the health services provided by the Greek National Health System (NHS). The satisfaction level assessment is examined in conjunction with demographic and socio-economic characteristics of the study participants, as well as with the characteristics that are related to their personal experience with the National Health System in Greece. The research was conducted from March 2012 to May 2013. The sample of the research comprises of 126 "first-generation" immigrants on legal permit of residence in Greece, who lived in the prefecture of Attica. It is panel study based on "snowball sampling" and the statistical analysis was conducted with the use of the Stata (ver. 11), while the statistical analysis used probit estimation techniques. The demographic and social variables-particularly the variables of gender, "understanding the Greek language", "education", "participation in the community of origin" and "insurance" - the variables of "health" and specifically "long-term diseases" and the variable of "trust" are found to be highly related with immigrants' satisfaction degree from the Greek health system. Our research concludes that health is a fundamental, human right and immigrants' access to health services is essential not only for their instant and effective treatment of their health problems and the improvement of their lives but also for ensuring the public health in Greece. In order to properly incorporate immigrants in Greece in particular, the health policy decision-makers have to pay attention to the contributing factors.
\end{abstract}

\section{Keywords}

National Health System in Greece, Immigrants, Access to Health Services, Satisfaction Level

\footnotetext{
${ }^{*}$ Corresponding author.
} 


\section{Introduction}

Immigrants constitute a vulnerable population group, a fact suggesting that they are facing an increased risk of social isolation. Their access to health services is one of the key parameters that contribute to their social inclusion, in the receptive society.

Nowadays, Greece, like all Western countries after all, has a new reality to manage, such as the one formed by the immigrant (and recently the refugees) phenomenon. Immigration to Greece began during the ' 80 s, was limited in terms of the number of immigrants the country could hold and in a legal form, while the majority of immigrants originated from Africa and Asia. During the '90s, after the “Eastern block's” collapse, Greece started receiving a large number of people coming from Central and Eastern Europe, thus, making Greece the country with the highest percentage of immigrants in the EU, in relation to its working force [1].

Since the mid-90s, the increase of immigrant flows toward Greece made the country number one in the percentage increase of incoming immigrants in the whole of Europe, with a large percentage of illegal immigrants. In 2012, of the total number of 10,815,197 residents, 537,273 were legal residents, while the number of illegal immigrants was estimated at 577,900 people [2].

Access of immigrants to health services in the country of reception constitutes a parameter that, on one hand, ensures the basic human rights and, on the other hand, contributes to the immigrants' social inclusion. Formal access of immigrants to the services of Greece's National Health System constitutes their formal employment and legal status. Immigrants, who possess legal rights to residency in Greece (Law. 2910/2001), enjoy the same rights as Greek citizens concerning national insurance and social protection. On the contrary, foreigners who reside in Greece without any legal documents of residency, have no right to access health services. The law excludes underage children and immigrants who are hospitalized as emergency cases (Article. 84, of Law 3386/ 2005) [3] [4].

However, legal immigrants who reside in Greece, also face significant obstacles when trying to access the health system, such as long waiting time in hospitals, deficient communication with health professionals, high cost (out-of-pocket payments) and complexity of the health system [1]. Additionally, foreigners are faced with financial insecurity at a greater degree than the native population, for the reason that their income is generally lower, while significant barriers are documented in the provision of information, concerning the Medicare and the immigrants' and refugees' ignorance in relation to their rights [5]-[7].

Similar research in Europe, has not detected significant inequalities versus the general population. In their research, Dixon and Woods et al. (2005) showed satisfactory immigrant access to Primary Health Care, documenting differentiations between the different ethnic groups [8]. The capacity to understand the language and the lack of sufficient information concerning health services were included within the basic parameters blocking the access.

Respective results of satisfactory access to health services are documented in research done in the Netherlands, where there is a very high percentage of immigrants on a European level [9]-[11].

Hjern et al. report equal access of immigrants to primary healthcare in Scandinavian countries, in relation to the native population, although immigrants are more likely to report dissatisfaction, in terms of healthcare needs being met and termination of therapy [12].

Finally, concerning Spain, the study of Carrasco-Gariddo et al. provided evidence that immigrants had higher hospitalization percentages than the Spanish population (11.4\% versus $8.2 \%$ ) [13]. Furthermore, the study of Cots et al. showed higher ratings for the use of the emergency room by immigrants [14]

Besides the serious issue of the access to health services, another crucial matter, that constitutes a widespread requirement of contemporary developed societies, is the quality for the provided health services.

Measurement of the patients' degree of satisfaction constitutes one of the most important parameters for documenting the quality of the health services and induces many benefits to the health units and, as an extension, to a wider social context.

Donabedian defined patient satisfaction as the outcome index of provided health services [15]. He claims that patient satisfaction reflects her opinion on the quality of healthcare services and represents specific qualitative features that are mainly related to the patient's expectations and values. Patient satisfaction, according to Yucelt, constitutes the confirmation, or not, of pursuit concerning the quality and effectiveness of the services provided [16]. While what a patient requires from a hospital is therapy, the inability to evaluate clinical care leads to a variety of other factors which affect one's judgment, such as the way health services deal with complaints, the health professionals' behavior, the immediacy of healthcare provision, the convenience of the services and, in general, the overall image of the hospital [17]. 
The main factors that contribute to the patients' satisfaction and that are documented through the questionnaire of the present study are concerned with the demographic features of patients (gender, age, family situation, education, profession, income), the relationship between healthcare professionals and patients, and the amount of the services provided rather than the quality [18] [19].

In contrast to North America and Australia, in Europe one rarely comes across studies that are concerned with recording data for the immigrant populations. (Sweden, the Netherlands and the United Kingdom are exceptions) [20]. However, despite of the fact that there are several reports of health status, access to care, treatment and survival for different minority groups, relatively few reports on patient satisfaction in these minority and immigrant groups are available [21]-[31]. In the USA, the National Quality Forum addressed measurement issues and challenges in reporting health care quality for minority populations and recommended improved race and ethnicity data collection practices for quality measurement [32]. Even if the target of this report was US racial and ethnic minorities, the immigrant population in other countries can also easily be considered as minority groups and thereby as having similar problems.

Our research paper aims at documenting the degree of immigrants' satisfaction with the health services provided to them by the Greek National Health System, through access and utilization of these services in relation to the effect of demographic and socioeconomic features of the participants, as well as the features that are associated with their experience thus far, through personal contact with their national health system.

\section{Methods}

\subsection{Study Population}

The present research study is a cross-sectional (panel), since the data collected regarded the years 2009-2011, and was conducted from Mars 2012 to May 2013 in Athens, Greece. The study population consisted of 126 immigrants (third country nationals) who were living in area of Athens. Regarding the sampling method, there is no accurate census of immigrants in Greece. Thus, probability or random sampling could not be realized and therefore snowball sampling (a nonprobability sampling method) was applied. Immigrants originated from various countries (of Asian, Africa and East Europe). Initially, we contacted key persons in immigrant communities, such as their leaders or representatives. Those key persons acted as mediators and between investigator and immigrants in order to increase feelings of trust and comfort. The mediators acted as interpreters also. Face-to-face interviews were conducted with immigrants with a mean duration of $15 \mathrm{~min}$. Through the abovementioned research design a high response rate (100\%) was achieved.

All participants were over 17 years, residing legally in Greece and were first-generation immigrants. Participants were informed about the study and gave their written consent. Personal data of immigrants were not registered at any stage of the study.

\subsection{Measures}

A questionnaire was developed including information on sociodemographic characteristics, health status, public health services knowledge and utilization and perception of difficulties in health services access. Sociodemographic characteristics included age, country of origin, years of stay in Greece, gender, marital status, number of children, educational level, health insurance coverage, employment at the time of study, personal and family monthly income, participation in community in the country of origin. Also, we measured immigrants' ability to understand, speak, read and write in Greek in a five-point Likert-type scale. Information about health status included self-reported health status and medication use for chronic diseases. Public health services knowledge was measured on a five-point Likert-type scale. Public health services utilization was measured for the years of study (2009-2011) and the degree of trustfulness the participants had in health professionals on a five-point Likerttype scale.

The final configuration of the questionnaire used, was based on the questionnaire of the previous study "Knowledge and Use of Health Services by Immigrants in Greece", where the study protocol was approved by the ethics committee of the Faculty of Nursing of the University of Athens [3].

\subsection{Statistical Analysis}

Stata (version 11) data analysis and statistical software was used for statistical analysis. 
Our Model encompasses the dependent variable (y) and thirteen independent variables $\left(\mathrm{x}_{\mathrm{s}}\right)$. The mathematical Model that will be estimated is the following: $\mathbf{y}_{\mathrm{it}}=\mathbf{f}(\mathbf{X}, \mathbf{Z}, \mathbf{H}, \mathbf{T})$, where:

$\mathbf{X}$ is a sum that encompasses demographic/social variables.

More specifically:

1) $x_{1}$ (gender), 2) $x_{2}$ (age), 3) $x_{3}$ (country), 4) $x_{4}$ (residence), 5) $x_{5}$ understanding), 6) $x_{6}$ (education), 7) $x_{7}$ (job), 8) $x_{8}$ (insurance) $\left.k \alpha 19\right) x_{10}$ (community)

$\mathbf{Z}$ is a sum that encompasses financial variables and more specifically:

10) $\mathrm{x}_{9}$ (income), 11) $\mathrm{x}_{12}$ (payment)

$\mathbf{H}$ is the variable that is concerned with the health condition of the participants. More specifically:

12) $\mathrm{x}_{11}$ (disease)

$\mathbf{T}$ is the variable that states the degree of trust the sampled immigrants feel toward the Greek Health system. More specifically:

13) $\mathrm{x}_{13}$ (trust)

The aforementioned model to be evaluated will be studied as linear. The dependent variable is distinctive and is given values 0 and 1 . Consequently, the model we used for the processing and statistical analysis of empirical data is a "probit" model and will be evaluated accordingly.

\section{Results}

Table 1 presents the participants' countries of origin:

Table 2 presents information regarding the immigrants' sociodemographic characteristics, their satisfaction with the NHS, their health status and their speaking level of the Greek language.

Based on the data presented above, the sample of immigrants in our research study tend, on average, to be

Table 1. Countries of origin of participants.

\begin{tabular}{|c|c|c|}
\hline Country of origin of participants & $\mathbf{N}$ & $\%$ \\
\hline Afghanistan & 2 & $1.59 \%$ \\
\hline Albania & 14 & $11.11 \%$ \\
\hline Bangladesh & 1 & $0.79 \%$ \\
\hline China & 1 & $0.79 \%$ \\
\hline Cuba & 1 & $0.79 \%$ \\
\hline Georgia & 14 & $11.11 \%$ \\
\hline Ghana & 4 & $3.17 \%$ \\
\hline Egypt & 3 & $2.38 \%$ \\
\hline Eretria & 2 & $1.59 \%$ \\
\hline Ethiopia & 25 & $19.84 \%$ \\
\hline India & 4 & $3.17 \%$ \\
\hline Iran & 2 & $1.59 \%$ \\
\hline Iraq & 1 & $0.79 \%$ \\
\hline Kenya & 4 & $3.17 \%$ \\
\hline Moldova & 1 & $0.79 \%$ \\
\hline Morocco & 1 & $0.79 \%$ \\
\hline Nigeria & 16 & $12.70 \%$ \\
\hline Pakistan & 20 & $15.87 \%$ \\
\hline Sierra Leone & 1 & $0.79 \%$ \\
\hline Syria & 3 & $2.38 \%$ \\
\hline Turkey & 1 & $0.79 \%$ \\
\hline Ukraine & 5 & $3.97 \%$ \\
\hline Total & 126 & $100 \%$ \\
\hline
\end{tabular}


Table 2. Statistical data description.

\begin{tabular}{|c|c|c|c|c|c|}
\hline Variable & Obs & Mean & Std. Dev. & Min & Max \\
\hline satisfaction & 141 & 0.6737589 & 0.4705081 & 0 & 1 \\
\hline gender & 378 & 0.452381 & 0.4983869 & 0 & 1 \\
\hline age & 378 & 1.722222 & 0.4659019 & 1 & 3 \\
\hline country & 378 & 11.51058 & 5.982835 & 1 & 22 \\
\hline residence & 378 & 13.43254 & 8.028056 & 0 & 38 \\
\hline understanding & 378 & 2.891534 & 1.051149 & 0 & 4 \\
\hline education & 378 & 2.873016 & 1.032502 & 1 & 5 \\
\hline job & 378 & 1.261905 & 0.6576855 & 0 & 4 \\
\hline insurance & 378 & 0.9206349 & 0.2657208 & 0 & 1 \\
\hline income & 378 & 707.4153 & 483.1436 & 0 & 4000 \\
\hline community & 375 & 0.384 & 0.4870077 & 0 & 1 \\
\hline disease & 378 & 0.2460317 & 0.4312681 & 0 & 1 \\
\hline payment & 143 & 0.1398601 & 0.348061 & 0 & 1 \\
\hline trust & 375 & 2.448 & 1.047962 & 0 & 4 \\
\hline
\end{tabular}

satisfied by the access to the Greek Health system, reside in Greece for about 13 years and, in their majority, are younger than 65 years of age-specifically between the ages of 30 to 64 . On average, their understanding of the Greek language is good (=3) and their academic level is of secondary (9 - 12 years of school attendance) and post-secondary (13 - 15 years of school attendance) education. The majority of the immigrants were employed in the private sector, while the overriding majority of the sampled individuals are insured, which is expected given the fact that our sample included immigrants residing legally in Greece and, as aforementioned, security of legal residency requires legal employment and vice versa. On average, immigrants had a monthly income of about $707 €$, while the mean number of participants did not belong/participate to a community/cultural organization at their country of origin, nor did any of them suffer from a chronic condition during the 3 years the study was carried out (2009-2011), a fact that would require one's regular visits (at least once every three months) to a healthcare facility.

Finally, on average, sampled immigrants had not been required to pay extra money for health services received by a public hospital during the 3 years of the study. Additionally, the participants expressed that their trust level toward the health professionals (doctors and nurses) of public hospitals and of their insurance carrier was moderate $(=2)$.

From the above data it occurs that the three independent variables:

- $\mathbf{x}_{10}$ (community)

- $\mathbf{x}_{11}$ (disease)

- $\mathrm{x}_{13}$ (trust)

are statistically significant in our model, while chi $2=0$ determines that there is a zero possibility for an incorrect estimation (see Table 3).

Table 4 determines that the research's dependent variable and the estimated dependent $\hat{y}$ (or y_hat) present similarities at about $61.5 \%$. Based on the specific correlation degree, we conclude that the estimated model satisfactorily explains the true data.

To continue with, we express the coefficients of Table 5 at an odds ratio.

The data of the above table suggest that the variables that determine the degree of the immigrants' satisfaction with the largest odds ratio (OR), are:

- The independent variable of gender which, when the condition changes (man to woman and vice versa), the probabilities of y being $y=1$, that is the probability that the immigrants are satisfied with the hospital personnel's response to the health problem they faced during the course of the study (2009-2011), are reduced by $\mathbf{5 1 \%}$. Meaning that, the degree of immigrants' satisfaction concerning the access they gain to the Greek health system, varies according to their sex at a percentage of $51 \%$.

- The independent variable of understanding, which puts forward the degree of understanding of the Greek 
Table 3. Probit results.

Iteration 0: $\log$ likelihood $=-87.129444$

Iteration $1: \log$ likelihood $=-60.919341$

Iteration 2: $\log$ likelihood $=-60.036189$

Iteration 3: $\log$ likelihood $=-60.027714$

Iteration 4: $\log$ likelihood $=-60.027711$

Logistic regression

Number of obs $=138$

LR chi2 $(12)=54.20$

Prob $>$ chi $2=0.0000$

Log likelihood $=-60.027711$

Pseudo R2 $=0.3111$

\begin{tabular}{|c|c|c|c|c|c|c|}
\hline Satisfaction & Coef. & Std. Err. & $\mathbf{Z}$ & $\mathbf{P}>|\mathbf{z}|$ & [95\% Conf. & Interval] \\
\hline gender & -0.7041091 & 0.5049579 & -1.39 & 0.163 & -1.693808 & 0.2855903 \\
\hline age & -0.0779157 & 0.5479484 & -0.14 & 0.887 & -1.151875 & 0.9960435 \\
\hline residence & 0.0390207 & 0.0368509 & 1.06 & 0.290 & -0.0332056 & 0.1112471 \\
\hline understanding & 0.173153 & 0.2903223 & 0.60 & 0.551 & -0.3958682 & 0.7421742 \\
\hline education & 0.3657477 & 0.2705502 & 1.35 & 0.176 & -0.1645209 & 0.8960163 \\
\hline job & -0.0639429 & 0.3931309 & -0.16 & 0.871 & -0.8344652 & 0.7065794 \\
\hline insurance & 0.5942555 & 1.207695 & 0.49 & 0.623 & -1.772784 & 2.961295 \\
\hline income & 0.0004521 & 0.0004838 & 0.93 & 0.350 & -0.0004962 & 0.0014004 \\
\hline community & -1.261027 & 0.5418181 & -2.33 & 0.020 & -2.322971 & -0.1990828 \\
\hline disease & 1.357208 & 0.5409311 & 2.51 & 0.012 & 0.2970021 & 2.417413 \\
\hline payment & 0.1579794 & 0.834384 & 0.19 & 0.850 & -1.477383 & 1.793342 \\
\hline trust & 1.420884 & 0.3287442 & 4.32 & 0.000 & 0.7765572 & 2.065211 \\
\hline _cons & -5.197037 & 2.0217 & -2.57 & 0.010 & -9.159496 & -1.234578 \\
\hline
\end{tabular}

Table 4. Correlation ŷ \& y.

\begin{tabular}{ccc}
\hline & pwcorr satisfaction y_hat & \\
\hline & satisf $\sim \mathrm{n}$ & y_hat \\
\hline satisfaction & 1000 & \\
y_hat & 0.6143 & 1000 \\
\hline
\end{tabular}

language by the sampled immigrants, which is altered when its status changes, then the probability of y being $y=1$ is raised by $\mathbf{1 9 \%}$. Meaning that, while the level of language understanding is raised, the probability of the immigrants being satisfied by their access to Greece's health system is also raised by $19 \%$

- The independent variable education, which represents the educational level of the sampled immigrants, which changes when its status is altered, i.e. when the immigrant's educational level is raised by passing from one academic level to the next, then the probability of the immigrant being satisfied with his/her access to the health system is raised by $\mathbf{4 4 \%}$.

- The independent variable insurance, which represents the number of years of insurance of our sample, which when its status is altered, then the probability of y being $\mathrm{y}=1$ is raised by $\mathbf{8 0 \%}$. In other words, when uninsured immigrants become insured, then the probability of them being satisfied by the Greek health system is raised by $80 \%$.

- The independent variable community, which puts forth the sampled immigrants' participation in communities of their country of origin, which, when its status is altered, the probabilities of $y=1$ decrease by $\mathbf{7 2 \%}$. To wit, when the immigrant transfers from not belonging to a community of his/her country of origin $(0=$ no), into belonging ( 1 = yes), then the probabilities of him/her being satisfied with the Greek health system decrease by $72 \%$.

- When the independent variable disease, which represents whether our sampled immigrants are suffering from a chronic disease $(0=$ no), changes status, then the probabilities of y being $y=1$, are raised by $\mathbf{2 8 8 \%}$. That is, when the immigrant passes into a condition in which he/she does suffer from a chronic condition (1 
Table 5. Probit results (odds ratio).

Iteration 0: $\log$ likelihood $=-87.129444$

Iteration 1: $\log$ likelihood $=-60.919341$

Iteration 2: $\log$ likelihood $=-60.036189$

Iteration 3: $\log$ likelihood $=-60.027714$

Iteration 4: $\log$ likelihood $=-60.027711$

Logistic regression

Number of obs $=138$

LR chi2 $(12)=54.20$

prob $>$ chi $2=0.0000$

Log likelihood $=-60.027711$

pseudo R2 $=0.3111$

\begin{tabular}{|c|c|c|c|c|c|c|}
\hline Satisfaction & Odds Ratio & Std. Err. & $\mathbf{Z}$ & $\mathbf{P}>|\mathbf{z}|$ & [95\% conf. & Interval] \\
\hline gender & 0.494549 & 0.2497264 & -1.39 & 0.163 & 0.1838181 & 1.330547 \\
\hline age & 0.9250424 & 0.5068755 & -0.14 & 0.887 & 0.3160437 & 2.707548 \\
\hline residence & 1.039792 & 0.0383172 & 1.06 & 0.290 & 0.9673396 & 1.117671 \\
\hline understanding & 1.189048 & -3452071 & 0.60 & 0.551 & 0.6730954 & 2.100497 \\
\hline education & 1.441591 & 0.3900228 & 1.35 & 0.176 & 0.8483 & 2.449824 \\
\hline job & 0.9380585 & 0.3687798 & -0.16 & 0.871 & 0.4341066 & 2.027046 \\
\hline insurance & 1.811682 & 2.187959 & 0.49 & 0.623 & 0.1698595 & 19.32297 \\
\hline income & 1.000452 & 0.000484 & 0.93 & 0.350 & 0.999504 & 1.001401 \\
\hline community & 0.2833629 & 0.1535312 & -2.33 & 0.020 & 0.0979821 & 0.819482 \\
\hline disease & 3.885329 & 2.101695 & 2.51 & 0.012 & 1.345818 & 11.2168 \\
\hline payment & 1.171142 & 0.9771822 & 0.19 & 0.850 & 0.2282342 & 6.009502 \\
\hline trust & 4.140779 & 1.361257 & 4.32 & 0.000 & 2.173975 & 7.886959 \\
\hline
\end{tabular}

= yes) and needs to visit a hospital regularly, then the probabilities of him/her being satisfied by his access to the NHS and the related services provided are raised by $288 \%$.

- The independent variable trust, which represents the degree of immigrants' trust toward health professionals (doctors-nurses) who belong to public Health or Insurance carriers, which when its status is altered, that is from no trust at all to some trust, or from a little trust to moderate or a lot and so on, then the probabilities of y being $\mathrm{y}=1$, i.e. the probabilities of the immigrants being satisfied by the personnel's response to the health problem they have encountered during the timeline of the study (2009-2011), are raised by 314\%. Therefore, this suggests that the more trust immigrants feel toward the health professionals, the higher the degree of satisfaction by the Greek health system.

\section{Discussion}

The findings of our study provide important information on immigrant satisfaction concerning the public health services provided in Greece. It was found that the demographic features of immigrants, and especially the gender variable (OR-51\%), the understanding of the Greek language (OR =19\%), and the education variable greatly contribute to the configuration of the degree of immigrant satisfaction concerning the health system.

Other researchers give prominence to the gender variable as a lead factor influencing the level of satisfaction, given that older patients tend to be more easily satisfied in comparison to younger individuals; however, these findings are negated by other studies [33] [34].

It is interesting how the family income of immigrants poses no contribution at all to the degree of their satisfaction with the Greek public health system. The findings of the present study suggest that the income variable does not affect at all (OR $=0 \%)$ the modulation of the degree of immigrant satisfaction. This finding demonstrates that the health services are provided by Greek public hospitals without the requirement to submit additional payment (we are referring to insured immigrant patients). Moreover, this finding is entirely differentiated by data derived from other relevant studies, which support that more prosperous individuals receive better healthcare that non-prosperous ones, even within the same service and, thus, are more satisfied in comparison to patients with a lower social status [29]-[31]. 
Immigrants' participation to a community of their country of origin seems to negatively affect the degree of their satisfaction, to a great extent. Our study findings, suggest that for an immigrant who is a member of a community of his/her country of origin (social, cultural, religious), the probabilities of him/her being satisfied by the Greek NHS), are decreased by $72 \%$. It is possible that this finding is owed to the fact that immigrants' participation to these communities formulates a protected environment, which covers their needs within this community, resulting in the deficient development/reinforcement of skills, such as, for example, learning the Greek language, which may enhance their social incorporation to the receiving country. Therefore, when immigrants need to come in touch with carriers of the Greek society, such as Greek hospitals, they encounter problems such as miscommunication, lack of knowledge concerning where they have to address their health needs, and end up dependent, to a great extent, on other members of their community who assume the role of mediator, interpreter, or escort to the health services, given that, as stated in other relevant studies, the complete lack of interpreters and mediators in public hospitals restricts the safekeeping quality health services [3] [4]. Studies conducted by Carrasquillo [35], Baker [36] and Morales [37], demonstrate the major influence of language knowledge or the provision of interpreters by the health system of the country of reception, on the degree of immigrant satisfaction.

From the findings of the present study, arises that immigrants who are health insured have $80 \%$ more probabilities of being satisfied with the health system. The specific finding, in harmony with the Greek legal framework, suggests that immigrant health insurance entails their access to health structures and, thus, constitutes an important factor for their satisfaction with health services. The most important influence on immigrant satisfaction with the health system is placed by the degree of trust that the immigrants themselves feel toward the health professionals of public hospitals and their insurance carrier. As is derived from our study, the more immigrants trust the health professionals, the higher are the probabilities that they will be satisfied by the health system, by an impressive $314 \%$.

Finally, the findings of the present study provide evidence that a $67 \%$ of immigrants are satisfied with Greek healthcare services. In a study carried out in the U.K., Dixon-Woods et al. (2005) report satisfactory immigrant access to health services [8]. Similar findings resulted from studies carried out in the Netherlands in Scandinavian countries and in Spain [10]-[13]. However, not all studies provide results of a high degree of immigrant satisfaction with the healthcare services provided in the country of reception. More specifically, in a previous study conducted in Greece in 2012 using Russian-speaking sample, a 31.5\% of respondents reported moderate satisfaction concerning the health services received in a public hospital, while the $44 \%$ was little or not satisfied at all [38]. Studies conducted in Europe [39]-[42], the U.S.A. [43]-[45] and Australia [46] [47], have provided evidence that non-western immigrants were less satisfied than natives. As a matter of fact, in a 2014 Special Eurobarometer, only 26\% of Greeks evaluate the quality of healthcare in Greece as being "good" [48].

Similarly, there other studies carried out in Europe [41], the U.S.A. [49] and Australia [47], which report a higher or the same degree of immigrant satisfaction by public health services in relation to natives.

Finally, Kambale places the demographic features of patients, and especially the immigrants' gender, profession, age, income and education level in a high position in relation to the degree of their influence on the patient's satisfaction by the provided health services [50].

There are some limitations in our study. The study population was not a random sample of immigrants in Greece, although an effort was made to include the major groups in proportions similar to those reported by recent statistical data. Additionally, larger scale studies, including rural areas in Greece, should be conducted in order to better understand the degree of satisfaction of immigrants with the Greek NHS.

The present study constitutes one of the very few relevant studies conducted in Greece on the specific issue and, although it was not possible to define a random sample from the whole immigrant population who reside legally in our country, we feel that the final results may satisfactorily represent the general immigrant population who reside legally in Greece and use daily the Greek health system.

\section{Conclusions}

The results of our study provided evidence that legal immigrants in Greece have access to Greek NHS, while the degree of satisfaction with those services is relatively high (67\%). Nevertheless, it must be emphasized that immigrants' reality is a hard one, because it is not enough to have legal residency, as mentioned, but also to be legally employed during periods when governmental and non-carrier research shows very high percentages of illegal employment within the Greek employment field. 
Finally, immigrants who do not possess any legal documents constitute another, even more vulnerable and marginal group, which is deprived of the ability to access a series of rights, such as the right to healthcare and requires greater attention and support.

\section{References}

[1] Papadaki, G. and Papapdaki, E. (2011) The Policy of Managing Migration Flows towards the European Union and Greece. 9th National Conference of Hellenic Regional Science Association, Panteion University, Athens. (In Greek)

[2] Hellenic Statistical Authority (EL.STAT.) (2012) Resident Population-Census 2011, EL.STAT., Athens.

[3] Galanis, P., et al. (2013) Public Health Services Knowledge and Utilization among Immigrants in Greece: A CrossSectional Study. BMC Health Services Research, 13, 350 http://dx.doi.org/10.1186/1472-6963-13-350

[4] Marantou-Alipranti, L. and Gazon, E. (2005) Immigration and Health Care. Assessment of the Current Situation. Challenges and Perspectives. National Center of Social Research-EKKE, Athens.

[5] Médecins du Monde (2011) Access to Healthcare for Undocumented Migrants in 11 European Countries. Report of the European Observatory, Médecins du Monde, European Observatory on Access to Healthcare, Paris.

[6] European Commission (2006) Equality in Health: Greek National Report. Edition of Directorate-General for Employment, Social Affairs and Equal Opportunities.

[7] European Commission (2006) The Demographic Future of Europe-From Challenge to Opportunity, Communication from the Commission, Commission of the European Communities com (2006) 571, Brussels.

[8] Dixon-Woods, M., Kirk, D., Agarwal, S., Annandale, E., Arthur, T. and Harvey, J. (2005) Vulnerable Groups and Access to Health Care: A Critical Interpretive Review. NCCSDO, London.

[9] Reijneveld, S.A. (1998) Reported Health, Lifestyles and Use of Health Care of First Generation Immigrants in The Netherlands: Do Socioeconomic Factors Explain Their Adverse Position? Journal of Epidemiology \& Community Health, 52, 298-304.

[10] Stronks, K., Ravelli, A.C.J. and Reijneveld, S.A. (2001) Immigrants in the Netherlands: Equal Access for Equal Needs? Journal of Epidemiology \& Community Health, 55, 701-707.

[11] Uiters, E., Devillé, W., Foets, M. and Groenewegen, P.P. (2006) Use of Health Care Services by Ethnic Minorities in The Netherlands: Do Patterns Differ? European Journal of Public Health, 16, 388-393.

[12] Hjern, A., Haglund, B., Persson, G. and Rosén, M. (2001) Is There Equity in Access to Health Services for Ethnic Minorities in Sweden? European Journal of Public Health, 11, 147-152.

[13] Carrasco-Garrido, P., Gil De Miguel, A. and Jiménez-García, R. (2007) Health Profiles, Lifestyles and Use of Health Resources by the Immigrant Population Resident in Spain. European Journal of Public Health, 17, 503-507.

[14] Cots, F., Castells, X., García, O., Riu, M., Felipe, A. and Vall, O. (2007) Impact of Immigration on the Cost of Emergency Visits in Barcelona (Spain). BMC Health Services Research, 7, 9-21. http://dx.doi.org/10.1186/1472-6963-7-9

[15] Donabedian, A. (1988) The Quality of Care: How Can It Be Assessed? The Journal of the American Medical Association, 260, 1743-1748.

[16] Yucelt, U. (1994) An Invetsigation of Causes of Patient Satisfaction/Dissatisfaction with Physician Services. Health Marketing Quarterly, 12, 11-28. http://dx.doi.org/10.1300/J026v12n02_03

[17] Kolter, P. and Clarke, R. (1987) Marketing for Health Care Organisation. Prentice-Hall, Inc., Englewood Cliffs.

[18] Tselepis, C. (2000) Satisfaction of the Health Service Users, Sociological and Psychological Approach of Hospitals. Health Services, Vol. A, Hellenic Open University, Patras, 158-164.

[19] Mirvis, D.M. (1998) Patient Satisfaction: Can Patients Evaluate the Quality of Health Care? Tennessee Medicine, 91, 277-279.

[20] Mladovsky, P. (2007) Research Note: Migration and Health in the EU. European Commission, Brussels.

[21] Venema, H.P.U., Garrestsen, H.F.L. and Van der Maas, P.J. (1995) Health of Migrants and Migrants Health Policy. The Netherlands as an Example. Social Science \& Medicine, 41, 809-818. http://dx.doi.org/10.1016/0277-9536(95)00065-F

[22] Perez, C.E. (2002) Health Status and Health Behaviours among Immigrants. Supplement to Health Reports. Statistics Canada, Ottawa, 1-12.

[23] Singh, G.K. and Siahpush, M. (2002) Ethnic-Immigrant Differentials in Health Behaviours, Morbidity and CauseSpecific Mortality in the United States. Human Biology, 74, 83-109. http://dx.doi.org/10.1353/hub.2002.0011

[24] Muennig, P. and Fahs, M.C. (2002) Health Status and Hospital Utilization of Recent Immigrants to New-York City. Preventive Medicine, 35, 225-231. http://dx.doi.org/10.1006/pmed.2002.1072 
[25] Leduc, N. and Proux, M. (2004) Patterns of Health Services Utilization by Recent Immigrants. Journal of Immigrant Health, 6, 15-27. http://dx.doi.org/10.1023/B:JOIH.0000014639.49245.cC

[26] Khan, S.A. and Ghosh, P. (2005) Medical Needs of Immigrant Populations. BMJ, 331, 418. http://dx.doi.org/10.1136/bmj.331.7514.418

[27] Wang, L. (2007) Immigration, Ethnicity and Accessibility to Culturally Diverse Family Physicians. Health \& Place, 13, 656-671. http://dx.doi.org/10.1016/j.healthplace.2006.10.001

[28] Hargreaves, S., Friedland, J.S., Gothard, P., et al. (2006) Impact on and Use of Health Services by International Migrants: Questionnaire Survey of Inner City London A\&E Attenders. BMC health Services Research, 6, 153. http://dx.doi.org/10.1186/1472-6963-6-153

[29] Mohanty, S.A., Woolhander, S., Himmelstein, D.U., Pati, S., Carrasquillo, O. and Bor, D.H. (2005) Health Care Expenditures of Immigrants in the United States: A Nationally Representative Analysis. American Journal of Public Health, 95, 1431-1438. http://dx.doi.org/10.2105/AJPH.2004.044602

[30] Uiters, E., Devillé, W.L., Foets, M. and Groenewegen, P.P. (2006) Use of Health Care Services by Ethnic Minorities in the Netherlands: Do Patterns Differ? European Journal of Public Health, 16, 388-393.

[31] Jansa, J.M. and Garcia de Olalla, P. (2004) Health and Immigrations: New Situations and Challenger. Gaceta Sanitaria, 18, 207-213.

[32] National Quality Forum (2002) Improving Health Care Quality for Minority Patients: Workshop Proceedings. National Forum for Health Care Quality Measurement and Reporting, Washington DC.

[33] Hall, J.A. and Dornan, M.C. (1988) What Patients Like about Their Medical Care and How Often They Asked: A Meta-Analysis of the Satisfaction Literature. Social Science \& Medicine, 27, 935-939. http://dx.doi.org/10.1016/0277-9536(88)90284-5

[34] Khayat, K. and Salter, B. (1994) Patient Satisfaction Surveys as s Market Research’ Tool for General Practices. British Journal of General Practice, 44, 215-219.

[35] Carrasquillo, O., Orav, E.J., Brennan, T.A. and Burstin, H.R. (1999) Impact of Language Barriers on Patient Satisfaction in an Emergency Department. Journal of General Internal Medicine, 14, 82-87. http://dx.doi.org/10.1046/j.1525-1497.1999.00293.x

[36] Baker, D.W., Hayes, R. and Fortier, J.P. (1998) Interpreter Use and Satisfaction Interpersonal Aspects of Care for Spanish-Speaking Patients. Medical Care, 36, 1461-1470. http://dx.doi.org/10.1097/00005650-199810000-00004

[37] Morales, L.S., Cunningham, W.E., Brown, J.A., Liu, H. and Hays, R.D. (1999) Are Latinos Less Satisfied with Communication by Health Care Providers? Journal of General Internal Medicine, 14, 409-417.

[38] Kotsioni, I. (2011) Access and Use of Healthcare Services by Migrants. Doctoral Thesis, National and Kapodistrian University of Athens, Medical School, Athens.

[39] Else, L. (2008) Non-Western Immigrants' Satisfaction with General Practitioners' Services in Oslo, Norway. International Journal for Equity in Health, 7, 7. http://dx.doi.org/10.1186/1475-9276-7-7

[40] Borde, T., David, M. and Kentenich, H. (2002) What Turkish-Speaking Women Expect in a German Hospital and How Satisfied They Are with Health Care during Their Stay in a Gynaecological Hospital in Berlin. A Comparative Approach. Gesundheitswesen, 64, 476-485. http://dx.doi.org/10.1055/s-2002-33775

[41] Ogden, J. and Jain, A. (2005) Patients’ Experiences and Expectations of General Practice: A Questionnaire Study of Differences by Ethnic Group. British Journal of General Practice, 55, 351-356.

[42] Mygind, A., Norredam, M., Nielsen, A.S., Bagger, J. and Krasnik, A. (2008) The Effect of Patient Origin and Relevance of Contact on Patient and Caregiver Satisfaction in the Emergency Room. Scandinavian Journal of Public Health, 36, 76-83. http://dx.doi.org/10.1177/1403494807085302

[43] Taira, D.A., Safran, D.G., Seto, T.B., et al. (1997) Asian-American Patient Ratings of Physician Primary Care Performance. Journal of General Internal Medicine, 12, 237-242. http://dx.doi.org/10.1007/s11606-006-5046-0

[44] Dallo, F.J., Borrell, L.N. and Williams, S.L. (2008) Nativity Status and Patient Perceptions of the Patient-Physician Encounter: Results from the Commonwealth Fund 2001 Survey on Disparities in Quality of Health Care. Medical Care, 46, 185-191. http://dx.doi.org/10.1097/MLR.0b013e318158af29

[45] Ngo-Metzger, Q., Legedza, A.T. and Phillips, R.S. (2004) Asian Americans’ Reports of Their Health Care Experiences. Results of a National Survey. Journal of General Internal Medicine, 19, 111-119. http://dx.doi.org/10.1111/j.1525-1497.2004.30143.x

[46] Small, R., Yelland, J., Lumley, J., Brown, S. and Liamputtong, P. (2002) Immigrant Women’s Views about Care during Labour and Birth: An Australian Study of Vietnamese, Turkish, and Filipino Women. Birth, 29, 266-277. http://dx.doi.org/10.1046/j.1523-536X.2002.00201.x 
[47] McLachlan, H. and Waldenström, U. (2005) Childbirth Experiences in Australia of Women Born in Turkey, Vietnam, and Australia. Birth, 32, 272-282. http://dx.doi.org/10.1111/j.0730-7659.2005.00370.x

[48] European Commission (2014) Patient Safety and Quality of Care. Special Eurobarometer 411 Report. European Commission, Directorate-General for Health and Consumers (DG SANCO), Brussels.

[49] Markova, T., Dean, F. and Neale, A.V. (2007) Health Care Attitudes and Behaviours of Immigrant and US-Born Women in Hamtramck, Michigan: A MetroNet Study. Ethnicity \& Disease, 17, 650-656.

[50] Kambale, J.M. (2010) Migrant Patients' Satisfaction with Health Care Services: A Comprehensive Review. Italian Journal of Public Health, 7, 69-81. 